
BONE MASS; EXPERIENCE OF A LIAISON SERVICE FRACTURE UNIT

Antonio Naranjo ${ }^{1}$, Soledad Ojeda ${ }^{2}$, Aida Saavedra ${ }^{2}$, Cristina Sepúlveda ${ }^{3}$, Amparo Molina ${ }^{3}$, Tatiana Marrero ${ }^{4}$, María Pino Afonso ${ }^{5}$, Margarita Ramirez ${ }^{6}$, Nieves Martín ${ }^{7}$, Alicia Olivares ${ }^{8}$, Carlos Rodriguez-Lozano ${ }^{3} .{ }^{1}$ Las Palmas de Gran Canaria, Rheumatology, Las Palmas de Gran Canaria, Spain, ${ }^{2}$ Hospital Universitario de Gran Canaria Dr Negrin, Rheumatology, LAS PALMAS DE G C, Spain, ${ }^{3}$ Hospital Universitario de Gran Canaria Dr Negrin, LAS PALMAS DE G C, Spain, ${ }^{4}$ Hospital Universitario de Gran Canaria Dr Negrin, Radiology, LAS PALMAS DE G C, Spain, ${ }^{5}$ Hospital Universitario de Gran Canaria Dr Negrin, Clinical Analysis, LAS PALMAS DE G C, Spain, ${ }^{6}$ Hospital Universitario de Gran Canaria Dr Negrin, Rheabilitation, LAS PALMAS DE G C, Spain, ${ }^{7}$ Hospital Universitario de Gran Canaria Dr Negrin, Rehabilitation, LAS PALMAS DE G C, Spain, ${ }^{8}$ Gerencia de atención primaria de Gran Canaria, LAS PALMAS DE GC, Spain

Background: The enigma of fragility fracture with normal bone mass; Experience of a Liaison Service Fracture Unit

Objectives: To describe the characteristics of patients with fragility fracture and normal DXA treated in an FLS unit.

Methods: Prospective 6-year observational study of a FLS fracture unit. Demographic variables, FRAX items, DXA and TBS were collected. The characteristics of patients with normal and abnormal DXA are described. The statistical analysis was performed by means of a descriptive, comparing the normal DXA/osteopenia/osteoporosis groups by means of contingency tables, Fisher's exact test, Student's $t$ test or ANOVA, as appropriate, as well as regression analysis.

Results: 1,631 patients were included, 205 with normal DXA $(12.5 \%)$, 747 with osteopenia $(45.8 \%)$ and 680 with osteoporosis (41.6\%). Patients with normal DXA were characterized by a higher percentage of males, a younger age and a higher BMI. Hip fracture was less frequent in patients with normal DXA, while the frequency of other fractures was higher. The frequency of previous fracture, history of hip fracture of the parents and secondary osteoporosis was lower in patients with normal DXA. The TBS and FRAX values were higher in the cases of normal DXA compared to osteopenia and osteoporosis. In the multiple regression analysis, excluding TBS, remained significant associated with abnormal DXA age (OR 1.04; 1.03-1.06), sex (OR 2.48; 1.71-3.58), BMI (OR 0.91; 0.89-0.94),) and parent hip fracture (OR 1.99; 1.11-3.58). Including TBS $<1,230$ as a dichotomous variable $(\mathrm{N}=451$ cases) remained significant age (OR 1.03; 1.00-1.06), sex (OR 3.58; 1.81-7.10) and TBS (OR 5.23; 1.55-17.68).

\begin{tabular}{|c|c|c|c|}
\hline & \multicolumn{3}{|c|}{ Bone densitometry } \\
\hline & Normal & Osteopenia & Osteoporosis \\
\hline $\mathbf{N}$ & 205 & 747 & 680 \\
\hline Sex (male), N $(\%)^{* *}$ & $54(26)$ & $140(19)$ & $84(12)$ \\
\hline Age in years, mean $(\mathrm{DE})^{* * *}$ & $68.8(10)$ & $71.3(9)$ & $74.2(10)$ \\
\hline BMI, mean $(\mathrm{DE})^{\star *}$ & $31.4(10)$ & $29.4(5)$ & $27.1(7)$ \\
\hline \multicolumn{4}{|l|}{ Type of fracture, $\mathbf{N}(\%)$} \\
\hline Forearm** & $75(36)$ & $284(38)$ & $206(30)$ \\
\hline Hip** & $21(10)$ & $188(25)$ & $148(22)$ \\
\hline Humerus** & $44(21)$ & $111(15)$ & $168(25)$ \\
\hline Spine* & $14(7)$ & $61(8)$ & $79(11)$ \\
\hline Others** & $51(25)$ & $102(13)$ & $76(11)$ \\
\hline \multicolumn{4}{|l|}{ FRAX items, N (\%) } \\
\hline Previous fracture** & $18(8)$ & $111(14)$ & $145(21)$ \\
\hline Parent's hip fracture** & $14(7)$ & $73(10)$ & $98(14)$ \\
\hline Smoking & $23(11)$ & $92(12)$ & $80(13)$ \\
\hline Corticoids & $14(7)$ & $51(7)$ & $42(6)$ \\
\hline Rheumatoid arthritis & $3(1)$ & $16(2)$ & $16(2)$ \\
\hline Secondary osteoporosis** & $24(12)$ & $117(15)$ & $150(22)$ \\
\hline Alcohol & $10(5)$ & $40(5)$ & $28(4)$ \\
\hline$>1$ fall in the last year, $N(\%) \mathbb{S}$ & $65(43)$ & $211(40)$ & $200(41)$ \\
\hline TBS, mean $(\mathrm{DE})$ ** & $1.220(469)$ & $1.166(426)$ & $1.115(435)$ \\
\hline Degraded TBS, N (\%)"*\& & $3(5)$ & $38(18)$ & $47(25)$ \\
\hline \multicolumn{4}{|l|}{ FRAX, mean (DE) } \\
\hline Major fracture*** & $5(3)$ & $9(5)$ & $18(10)$ \\
\hline Hip fracture** & $1(1)$ & $3(3)$ & $9(8)$ \\
\hline
\end{tabular}

${ }^{*} \mathrm{P}<0.05 ;{ }^{* *} \mathrm{P}<0,01 ; \mathrm{S}$ analyzed in 1,161 patients; \& analyzed in 451 patients
Conclusion: Patients with fragility fracture and normal DXA are younger, with more frequent males and with BMI and higher TBS values.Acknowledgement: Fabiola Santana y Carmen Alonso

Disclosure of Interests: Antonio Naranjo Grant/research support from: Amgen, Consultant for: UCB, Speakers bureau: Amgen, UCB, Soledad Ojeda Grant/research support from: AMGEN, Speakers bureau: AMGEN Aida Saavedra: None declared, Cristina Sepúlveda: None declared, Amparo Molina Speakers bureau: AMGEN, Tatiana Marrero: None declared, María Pino Afonso: None declared, Margarita Ramirez: None declared, Nieves Martín: None declared, Alicia Olivares: None declared, Carlos Rodriguez-Lozano: None declared DOI: 10.1136/annrheumdis-2019-eular.2272

\section{AB0845 EFFECTIVENESS AND SAFETY OF BISPHOSPHONATES IN THE TREATMENT OF SECONDARY OSTEOPOROSISIN CHILDREN}

Julia Ferrero Turrión, Rocío Galindo Zavala, Esmeralda Núñez Cuadros, Gisela Diaz-Cordobes, Laura Martín Pedraz, Antonio Urda Cardona. Hospital Regional Universitario de Málaga, Málaga, Spain

Background: Prevalence of secondary osteoporosis (SO) in children is an ongoing challenge, due to the rise in life expectancy of chronic diseases and the bone toxicity medication usage. Bisphosphonates (BF) has been stated as an alternative therapy, although studies targeted children are few.

Objectives: The goal was to establish the effectiveness and safety of bisphosphonate therapy in children with SO.

Methods: A retrospective study of BF treatment in children ( $\leq 16$ years) with SO at a Pediatric Reumathology Unit from 2015 to 2018.

Descriptive statistics were performed to examine anthropometric measurements, clinical features, diagnoses and treatment received. We measured bone mineral density by dual-energy $x$-ray absorptiometry and we expressed the results as adjusted for height-for-age Z-score (HAZ)

We assessed the treatment outcome by the change of HAZ after a year treatment and the decreasing fractures rate per year.

Afterwards we made a bivariate analysis to identify related factors with effectiveness and safety of bisphosphonates. Values of $p<0,1$ were considered statistically significant.

Results: In our study 12 patients were treated with BF, three of them with two different type. Table 1 shows the descriptive data.

The HAZ and the fracture rate per year after a year of treatment were significantly lower $[(-2,22 \pm 1,46)$ vs $(-1,06 \pm 1,27) ; p=0,04$, and $(1(0,5-2)$ vs $0(0-0) ; p<0,01)$, respectively]

Table 1. Descriptive analysis

\begin{tabular}{|c|c|}
\hline \multicolumn{2}{|c|}{ Demographic features and anthropometric measurements $(\mathrm{n}=12)$} \\
\hline Males, $\mathrm{n}(\%)$ & $9(75)$ \\
\hline Age (years), mean $( \pm \mathrm{SD})$ & $9,8( \pm 1,87)$ \\
\hline BMI SD, mean ( $($ SD) & $1.03( \pm 2,36)$ \\
\hline \multicolumn{2}{|l|}{ Clinical features of the patients, $(\mathrm{n}=12)$} \\
\hline \multicolumn{2}{|l|}{ Secondary osteoporosis cause, n (\%) } \\
\hline Neurologic & $6(50)$ \\
\hline Hematologic & $5(41,7)$ \\
\hline Before treatment fractures, mean $( \pm \mathrm{SD})$ & $1.41( \pm 1,16)$ \\
\hline Vertebral fractures (Yes), n (\%) & $7(58,3)$ \\
\hline $\mathrm{Z}$ score* before treatment, mean $( \pm \mathrm{SD})$ & $-2.40( \pm 1,31)$ \\
\hline Age at first fracture (years), mean $( \pm \mathrm{SD})$ & $8,2( \pm 3,4)$ \\
\hline \multicolumn{2}{|c|}{ Bisphosphonates treatment features of the patients $(\mathrm{n}=15)$} \\
\hline Drug administration via (iv), n (\%) & $8(53,3)$ \\
\hline \multicolumn{2}{|l|}{ Bisphosphonate type, $\mathrm{n}(\%)$} \\
\hline Pamidronate & $1(6,7)$ \\
\hline Alendronate & $6(40)$ \\
\hline Zoledronate & $7(46,7)$ \\
\hline Risendronate & $1(6,7)$ \\
\hline Treatment duration (months), median (Range) & $19(11-63)$ \\
\hline Treatment ending, n (\%) & $8(53,3)$ \\
\hline \multicolumn{2}{|l|}{ Cause of treatment ending, $\mathbf{n}(\%)$} \\
\hline $\mathrm{HAZ}>-2$ and lack of fractures after a year & $5(62.5)$ \\
\hline Adverse effects & $1(12,5)$ \\
\hline Exitus*1 & $2(25,5)$ \\
\hline \multicolumn{2}{|l|}{ Adverse effects, $\mathrm{n}(\%)$} \\
\hline Flu-like syndrome & $2(13,3)$ \\
\hline Asymptomatic hypocalcemia & $1(6,7)$ \\
\hline Gastrointestinal intolerance & $1(6,7)$ \\
\hline
\end{tabular}

*' Due to underlying disease complications 
The change at $\mathrm{HAZ}$ and the before treatment fractures rate per year $(r: 0,57 ; p=0,07)$ were directly proportional. Also, the change at HAZ was inversely proportional to the before treatment Z-score $(r:-0,53 ; p=0,09)$ and the BF starting age ( $r$ : $-0,53 ; p: 0,09$ )

The decrement of fractures rate per year showed a statistical significant relationship with BMI percentile $(r: 0,48 ; p=0,08)$, the treatment starting age $(r:-0,537 ; p=0,05)$ and before treatment fractures rate per year $(r: 0,941$; $\mathrm{p}<0,001)$.

Three patients experienced adverse effects (20\%). Three related to zoledronate use: two of them showed flu-like syndrome after first infusion and the other asymptomatic hypocalcemia. In another patient the treatment with alendronate was ended due to gastrointestinal intolerance.

There was not significant relationship between adverse effects and our study variables.

Two patients died during the treatment due to their underlying disease complications.

Conclusion: BF are an effective medication for SO. The treatment outcome exhibits to be better with a good nutritional status, younger age and at more severe forms of the disease. Additionally, they are safe showing just minor adverse effects but often.

\section{REFERENCES}

[1] Galindo Zavala R, Núñez Cuadros E, Díaz Cordovés-Rego G., Urda Cardona, AL. Advances in the treatment of secondary osteoporosis. An Pediatr (Barc). 2014; 81(6): 399.e1-399.e7.

[2] Zemel BS, et al. Height adjustment in assessing dual energy x-ray absorptiometry measurements of bone mass and density in children. J Clin Endocrinol Metab.2010; 95(3): 1265-73.

[3] Gordon CM, Leonard MB, Zemel BS. 2013 pediatric position development conference: Executive summary and reflections. J Clin Densitom. 2014;17 (2): 219-24.

Disclosure of Interests: Julia Ferrero Turrión: None declared, Rocío Galindo Zavala Grant/research support from: NOVARTIS, ABBVIE (ALWAYS AS SPEAKER), Speakers bureau: NOVARTIS, ABBVIE, Esmeralda Núñez Cuadros Grant/research support from: NOVARTIS, ABBVIE, ROCHE (ALWAYS AS SPEAKER), Speakers bureau: NOVARTIS, ABBVIE, ROCHE, Gisela Diaz-Cordobes Grant/research support from: ABBVIE, ROCHE (ALWAYS AS SPEAKER), Speakers bureau: ABBVIE, ROCHE, Laura Martín Pedraz: None declared, Antonio Urda Cardona Grant/ research support from: PFIZER (ALWAYS AS SPEAKER), Speakers bureau: PFIZER

DOI: 10.1136/annrheumdis-2019-eular.5075

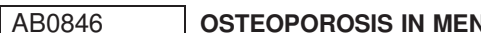

Vitaliy Polyakov ${ }^{1}$, Gleb Kravtsov ${ }^{1}$, J Polyakova ${ }^{2}$, B Zavodovsky ${ }^{2} .{ }^{1}$ Volgograd State Medical University, Volgograd, Russian Federation; ${ }^{2}$ Federal State Budgetary Institution «Research Institute of Clinical and Experimental Rheumatology named after A.B. Zborovsky", Volgograd, Russian Federation

Background: Careful attention to postmenopausal osteoporosis (OP) leads to an underestimation of this problem in men.

Objectives: To assess the frequency of bone mineral density reduction (BMD) in men referred for examination, analysis of bone mineralization disorders in men at different age periods, the main reasons for referral for examination.

Methods: During the year, a two-energy X-ray absorption osteodensitometry (LUNAR XP, USA) was examined by 2,731 patients according to a standard program.

Results: Among the 2731 patients referred for examination, the proportion of men is $5 \%$, men over 60 years old are $2 \%$, male children and teenagers are $0.29 \%$. Normal BMD was detected in $31.88 \%$, low bone mass (LBM) - in $39.86 \%$, OP - in $28.26 \%$.

$60.14 \%$ (83 people) - men of young and middle age, NCM was detected in 33 men, OP - in 14. In 8 - severe form. Reduced BMD patients revealed the presence of serious underlying disease (ankylosing spondylitis, rheumatoid arthritis (RA), systemic lupus erythematosus, diabetes mellitus I type, diffuse toxic goiter disease operated stomach, ulcerative colitis, chronic autoimmune hepatitis and alimentary toxic hepatitis with outcome in cirrhosis of the liver, bronchial asthma (BA), alveolitis.

Elderly and senile men among the surveyed were 55 people (39.86\%), LBM - in 22 of them, OP - in 25. Low traumatic fractures in the anamnesis in this group of patients were detected in 13 of 55 . In 6 - multiple vertebral fractures, in 2 - multiple repeated fractures of tubular bones. Secondary causes of a decrease in BMD were detected only in 5 out of
$55(9.09 \%)$ men aged 60 years and older (RA, BA, idiopathic alveolitis, liver cirrhosis; all currently or with a history of glucocorticoid therapy). Normal BMD was detected in 44 men. Up to 59, their number was 36 people $(81.8 \%), 60$ years and older - only $8(18.2 \%)$. The majority of men with normal BMD indices were sent for examination by dentists endocrinologists, orthopedic traumatologists. 5 adolescents with BMD in accordance with normal age criteria BMD had repeated traumatic bone fractures in history (fractures during sports (wrestling, football)).

Conclusion: Unlike women, men do not pay enough attention to the prevention of $\mathrm{OP}$, often use dairy products in limited quantities, do not take calcium preparations for prophylactic purposes. A high percentage of the population is characterized by low physical activity. Men more often than women abuse alcohol and smoking.

OP occurs without obvious clinical manifestations until the moment of fracture of the skeleton bones, primary care physicians and hospitals have low alertness for the detection of OP in men. FRAX (fracture risk assessment tool) makes it easy to calculate the probability of a 10-year risk of fractures and identify men at high risk for further examination. The urgency of the problem is due to the increase in the average life expectancy of a modern person.

\section{REFERENCES}

[1] Problemy diagnostiki nizkotravmatichnyh perelomov pozvonkov u lic starshego vozrasta. Pisareva V., Mihajlov M., Poljakov V.[et al]. Russian Journal of Pain. 2018. V.56.(2).P.90-1.

[2] Issledovanie rasprostranennosti osteoporoza, ego oslozhnenij i znachimosti faktorov riska/Zavodovskij B., Sivordova L., Poljakova Ju.[et al]. Palliative medicine and rehabilitation. 2015. 2. P.9-12.

[3] Osteoporosis in men: current issues. Simakova E., Seewordova L.[et al] Uspekhi Gerontologii. 2015. V28(1). P 77-9.

Disclosure of Interests: None declared

DOI: 10.1136/annrheumdis-2019-eular.7330

\section{AB0847 INCIDENCE RATES OF OSTEOPOROSIS(OP) RISK FACTORS IN A LARGE URBAN LONDON BOROUGH}

Rizwan Rajak ${ }^{1}$, Amanda Perren ${ }^{1}$, Suma Mahendrakar², Momina Zaman ${ }^{3}$, LI Elaine $^{4}$, Michael Kotrba ${ }^{5}$, Amanda Humphreys $^{2}$, Joseph Rehman ${ }^{2}$, Wallace Tan ${ }^{2}$, Fathi Al-Jehani ${ }^{6}$, Suzy Peerman ${ }^{7} .{ }^{1}$ Croydon Health Services NHS Trust, Rheumatology, Croydon, United Kingdom; ${ }^{2}$ Croydon Health Services NHS Trust, Geriatrics, Croydon, United Kingdom; ${ }^{3}$ St George's University Hospital NHS Trust, Rheumatology, Tooting, United Kingdom; ${ }^{4}$ Croydon Health Services NHS Trust, FLS Service, Croydon, United Kingdom; ${ }^{5}$ Croydon Health Services NHS Trust, Orthopaedics, Croydon, United Kingdom; ${ }^{6}$ Croydon Health Services NHS Trust, Haematology, Croydon, United Kingdom; ${ }^{7}$ Croydon Health Services NHS Trust, Physiotherapy, Croydon, United Kingdom

Background: Identification of osteoporosis risk factors(OPRFs) is a necessary part of assessing fracture risk and treating patients with OP. Incidence rates of OPRFs are variably reported in the literature. Patients seen in OP clinics tend to have a higher risk of fractures compared to those managed in primary-care hence the need for closer scrutiny of their OPRFs. In some instances, managing modifiable OPRFs may form the principle part of the patient's management plan.

Objectives: We examined the rates of OPRFs in patients attending the Bone Health Clinic at Croydon Health Services NHS Trust.

Methods: Retrospective review of OP patients seen between FebruaryJune 2018 at Purley Memorial Hospital and assessed for presence of OPRFs including: demographics,BMI,early menopause,late menarche,nulliparity,secondary medical conditions, medicines,family history of OP/parental hip fracture,recurrent falls,previous fragility fractures(FFs) and lifestyle OPRFs(smoking,alcohol,low calcium intake,sedentary).

Results: 201 patients were included. Mean age was 70-years-old (range:37-96), with approximately 9:1 female:male ratio. Mean BMI was 23 (normal) with approximately $20 \%$ being $<18.5$ (underweight). $25.5 \%(46 /$ 180 -females) experienced an early menopause(<45-years) but only $8.3 \%$ $(15 / 180)$ had late menarche(>16years). Of the $25.5 \%$ with early meno pause, only $13 \%(6 / 46)$ had been offered HRT. $17 \%$ of women were nulliparous. Of the medical conditions, thyroid disease was the most commonly reported $(18 \%)$ with a third of these being newly diagnosed in clinic. Coeliac was identified in $7.5 \%$ with $5 \%$ newly diagnosed. $2 \%$ had newly diagnosed haematological disorders (MGUS,Myeloma,Lymphoma). Only 8 patients had 2-or-more diagnoses at the same time. Almost $40 \%$ had a family history of OP, $19 \%$ history of parental hip fracture and $15 \%$ had both. The majority $66.7 \%(134 / 201)$ had experienced a previous FF with $36 \%$ having suffered 2 or more. $16 \%(32 / 201)$ had experienced 